\title{
Will Unchecked Global Warming Destroy Civilisation by Century's End? What Three Degrees of Global Warming Really Means ${ }^{1}$
}

\author{
Peter Barrett
}

A temperature change of $3^{\circ} \mathrm{C}$ is something we experience wherever we are on earth every day - in fact a typical daily change in most places is more like 8 or $9^{\circ} \mathrm{C}$. In the past few years scientists have become conceraned because global temperature has risen $0.6^{\circ} \mathrm{C}$. So why the fuss?

In November 2004 at the annual Royal Society of New Zealand's awards dinner I said that if we ('first world' countries) continue on our current path, a warming of this magnitude would risk 'the end of civilisation as we know it by the end of this century'. This seems like an absurd claim, but the words reflect my judgement from the perspective of three decades of research into the last 40 million years of past Antarctic climate. My key point, though, was that this gloomy prospect is not inevitable if we respond to the problem now. Let me explain.

Geologists now know a great deal about changes in climate on a range of timescales. For example, we know the earth has cooled around $4^{\circ} \mathrm{C}$ over the last 40 million years (see Figure 1). We also know this long-term cooling trend has regular fluctuations every 40,000 or 100,000 years superimposed on it, and these have been almost as large (in fact larger in the last million years or so) (see Figure 2). We are also learning from climate research that after 1,000 years of stable climate, a 40million-year decline in temperature may be largely reversed by the end of this century (see Figure 3). Firstly, I'll outline the basis for this assessment, and then briefly review the disastrous consequences of such a warming according to environmental scientists.

An international group of hundreds of leading scientists and other experts nominated by governments around the world ${ }^{2}$ concluded in 2001 that if current trends in greenhouse gas emissions continue unchecked to 2100 , when $\mathrm{CO} 2$ is projected to be double pre-industrial levels, we could expect global temperature to rise somewhere between 1.4 and $5.8^{\circ} \mathrm{C}$. A workshop sponsored by this group, the Intergovernmental Panel on Climate Change (IPCC), concluded in 2004 that improved modelling studies were converging on $3^{\circ} \mathrm{C}^{3}$ as the most likely temperature rise for a doubling of $\mathrm{CO} 2$ levels. This means that by the end of the century, if greenhouse gas emissions continue to rise unchecked, there is a 50-50 likelihood that temperatures will be at least $3^{\circ} \mathrm{C}$ warmer - a huge risk if the consequences are serious.

Such a rise is not far short of the $4^{\circ} \mathrm{C}$ that would return the earth, in an instant of geological time, to its climate around 40 million years ago, long before even our ancestral genus Homo evolved a mere 6 or 7 million years ago. Forty million years ago the earth was very different from the one we know today. Large mammals had yet to evolve, India had not yet collided with Asia to form the Himalayas, Antarctica was free of ice and covered with beech forest, and global sea level was 70 metres higher. In ten human generations (from 1900 to $2100 \mathrm{AD}$ ) we will have largely completed the reversal of the global cooling trend that took place naturally over 20 million generations.

1 This article is reprinted from Pacific Ecologist, 11, December 2005, with the editor's permission.

2 The Intergovernmental Panel on Climate Change (IPCC) was established under the aegis of the United Nations Environment Programme and the World Meteorological Organization in 1988. It accepts only peer-reviewed publications for consideration as evidence. The IPCC is made up of governments, not scientists. However, scientists write the reports that the IPCC approves, following a rigorous multiple peer-review process. IPCC was established to provide governments and the wider community with carefully considered reports on the changes being widely perceived in regional and global climate in the 1980s, and possible links with increasing greenhouse gases in our atmosphere. It has published reports thus far in 1990, 1995 and 2001, and another is due in 2007. These document with increasing certainty the influence of humaninduced greenhouse gas pollution on the earth's atmosphere and climate. Their reports can be downloaded from www.ipcc.ch. The summaries for policy makers are especially useful.

3 See note 2 
Fortunately, we have yet to feel the full effects of the current level of greenhouse gas pollution. Even the unstable regions of the Antarctica's ice cover (e.g. the West Antarctic Ice Sheet, which would raise sea level 6 metres if it all went into the sea) are likely to take at least decades to respond. However part of the delay in warming is from 'global dimming', ${ }^{4}$ with attendant cooling from atmospheric pollution by smoke and dust. But this delay in global warming will be short-lived because improvements in pollution control are restoring clear skies.

Other news is also not good. Arctic warming is accelerating, causing thinning of the floating ice that covers the Arctic Ocean, and melting of glaciers and large areas of permafrost, causing many adverse ecological and environmental consequences. ${ }^{5} \mathrm{Mid}$ and low latitude glaciers are also mostly retreating, despite a misleading report to the contrary which was exposed by Guardian Weekly columnist George Monbiot. ${ }^{6}$

Furthermore, the Antarctic ice sheet is turning out to be more responsive to regional temperature changes than most of us expected, not only through collapsing ice shelves in the Antarctic Peninsula, but also with satellite measurements showing huge ice streams draining the Pacific sector of the West Antarctic Ice Sheet faster by a factor of 10 , resulting in sea level rising another 0.18 $\mathrm{mm} /$ year. ${ }^{7}$ This is only partially balanced by the increase in snowfall in East Antarctica (resulting in a sea level rise of $0.12 \mathrm{~mm} /$ year). Continued warming will only increase the rate of global sea level rise through further Antarctic melting. This is additional to the rise in sea level from the upper layers of the ocean expanding from the global warming of the last few decades ${ }^{8}$ - further proof that the rise in global temperatures shown in Figure 3 is real.

Other consequences around Antarctica are a freshening of the Ross Sea from increased melting, ${ }^{9}$ and a decline in sea ice extent of $20 \%$ since the $1950 .{ }^{10}$ Sea ice is one of the main forces driving the global ocean heat conveyor belt that moderates temperatures on the earth's surface (and also delivers oxygen to maintain life in the deep oceans). If the polar regions lose their sea ice, and melting ice from Greenland freshens the North Atlantic, then the Gulf Stream that now warms north-west Europe will slow and this region will cool by several degrees. ${ }^{11}$

But what would be the consequences of these changes? The global situation has been reviewed recently in a report prepared for the G8 group of countries entitled Meeting the Climate Challenge, ${ }^{12}$ and released in January 2005. The report identifies just $2^{\circ} \mathrm{C}$ (and an atmospheric $\mathrm{CO} 2$ level of $400 \mathrm{ppm}$ (parts per million), which is $43 \%$ above the pre-industrial level of $280 \mathrm{ppm}$ ) as the danger level for global warming. It is worth noting that the earth has not experienced such a high $\mathrm{CO} 2$ level in the last 25 million years. ${ }^{13}$ The report spells out the likely consequences:

Beyond the $2^{\circ} \mathrm{C}$ level, the risks to human societies and ecosystems grow significantly. It is likely, for example, that average temperature increases larger than this will entail substantial agricultural losses, greatly increase numbers of people at risk of water shortages, and have widespread adverse health impacts.

The report goes on to say: "[This] could also imperil a very high proportion of the world's coral reefs and cause irreversible damage to important terrestrial ecosystems, including the Amazon rainforest.' It concludes:

Above the $2^{\circ} \mathrm{C}$ level, the risks of abrupt, accelerated, or runaway climate change also increase. The possibilities include reaching climatic tipping points leading, for example, to the loss of the West Antarctic and Greenland

4 Wild et al. (2005) 'From dimming to brightening: decadel changes in solar radiation at earth's surface', Science, 308, pp.847-50; Pinker et al. (2005) 'Do satellites detect trends in surface solar radiation?', Science, 308, pp.850-54.

5 ACIA (2004) Impacts of a Warming Arctic: Arctic climate impact assessment, Cambridge: Cambridge University Press, http:// www.acia.uaf.edu.

6 Monbiot, G. (2005) 'Junk science', Guardian Weekly, 10 May, http:/ /www.monbiot.com/archives/2005/05/10/junk-science/

7 Thomas, R. et al. (2004) 'Accelerated sea level rise from West Antarctica', Science, 306, pp.355-8.

8 Barnett, T.P. et al. (2005) 'Penetration of human-induced warming into the world's oceans', Science, 309, pp.284-7.

9 Jacobs, S.S. et al. (2002) 'Freshening of the Ross Sea during the late 20th century', Science, 296, pp.386-9.

10 Curran, M.A. et al. (2003) 'Ice core evidence for Antarctic sea ice decline since the 1950s', Science, 302, pp.1203-6.

11 http://www.cru.uea.ac.uk/cru/info/thc/.

12 International Climate Change Taskforce (2005) Meeting the Challenge, http://www.stabilisation2005.com/outcomes.html.

13 Pearson, P.N. and M.R. Palmer (2000) 'Atmospheric carbon dioxide concentrations over the past 60 million years', Nature, 406, pp.6959; Royer, D.L. et al. (2001) 'Paleobotanical evidence for near present day levels of atmospheric $\mathrm{CO} 2$ during part of the Tertiary', Science, 292, pp.2310-3. 
ice sheets (which, between them, could raise sea level more than 10 metres over the space of a few centuries), the shutdown of the thermohaline ocean circulation (and, with it, the Gulf Stream), and the transformation of the planet's forests and soils from a net sink of carbon to a net source of carbon.

All of this is coming at a time when the earth's ecosystems are already stressed by destructive development practices and an over-populated planet. A review entitled The Millennium Ecosystem Assessment,${ }^{14}$ carried out under the aegis of the United Nations Environment Programme, was released in May 2005 after four years work by 1,300 scientists. It begins with the recognition that the human species, while buffered against environmental changes by culture and technology, is fundamentally dependent on the flow of ecosystem services. It was barely noticed by the media, but its conclusions touch us all.

- First, approximately 60\% (15 out of 24 ) of the ecosystems examined are being degraded or used unsustainably, including in terms of fresh water, capture fisheries, air and water purification, and the regulation of regional and local climate, natural hazards and pests.

- Second, it is established, though evidence is incomplete, that ecosystem degradation is increasing the likelihood of unexpected changes in ecosystems, with serious consequences for human well-being. Examples include: disease emergence, abrupt alterations in water quality, the creation of 'dead zones' in coastal waters, collapse of fisheries and shifts in regional climate.

- Third, the harmful effects of the degradation of ecosystem services are being borne disproportionately by the poor, and are in places the main factor causing poverty and social conflict.

These problems will be exacerbated by global warming.

The situation is in fact worse than these reports describe, simply because of the time lag of several years in the results being reported and disseminated. We have only a few years left, maybe ten at most, to change societal attitudes towards progress before we have 'lit the fuse' for inevitable environmental catastrophe in later decades. As Ronald Wright explains, it is the Victorian notion of progress through economic growth and exploitation of resources (with only immediate costs considered) that is fast leading us to environmental crisis and collapse. ${ }^{15}$ The UN Framework Convention on Climate Change of 1988 was a start, and the Kyoto Protocol, which came into effect only this year, continues, albeit slowly, in the right direction. The G8 meeting in July 2005 has at least agreed there is a problem. ${ }^{16}$ Both developed and developing countries sorely need an immediate and sustained focus on political and economic mechanisms for returning us to the $1990 \mathrm{CO} 2$ emission levels sought by the Kyoto Protocol. Even if this is achieved it will take decades for atmospheric $\mathrm{CO} 2$ levels to decline.

Despite the scale of the global warming problem, we have good reason to be optimistic. Technological developments in the last few decades have brought about huge efficiencies in capturing renewable energy from wind, sun, waves and tides. The over-consumption of oil, that most convenient of all transport energy sources, has to be addressed, but the answer there is easy to see in improved public transport and lighter, more efficient cars. Pressures to move in this direction are increasing, with air pollution in cities and the rising cost of extracting oil as demand outstrips supply. 'Hubbert's peak' approaches and it becomes increasingly expensive to deliver. Unfortunately, nuclear power is not a costeffective substitute for oil or coal, for reasons explained by Peter Bunyard. ${ }^{17}$

At the same time, many people in the developed world have become weary of the consumerism of the last few decades and the ill health that follows from fast lives and fast food. After achieving an energy-intensive lifestyle that has led the rest of the world in atmospheric pollution, we are discovering through film, television, museums and antiquities the pleasures and achievements of successful societies of the past. Of course, many past societies have failed, but, most importantly, ours is the best equipped of all to learn from those successes and failures, as anthropologist Jared Diamond has recently observed. ${ }^{18}$ If we really deserve the name we have given

14 Millennium Ecosystem Assessment Synthesis Report, 2005, http:// www.millenniumassessment.org//en/Products.Synthesis.aspx.

15 Wright, R. (2005) A Short History of Progress, New York: Carroll and Graf Publishers

16 http://en.wikipedia.org/wiki/31st_G8_summit\#Global_warming.

17 Bunyard, P. (2005/6) 'Taking the wind out of nuclear power', Pacific Ecologist, 11, pp.51-7.

18 Diamond, J. (2005) Collapse: how societies choose to fail or succeed, London: Penguin. 


\section{PolicyQuarterly}

Figure 1: Temperature over the last 80 million years based on the deep-sea isotope record. ${ }^{20}$

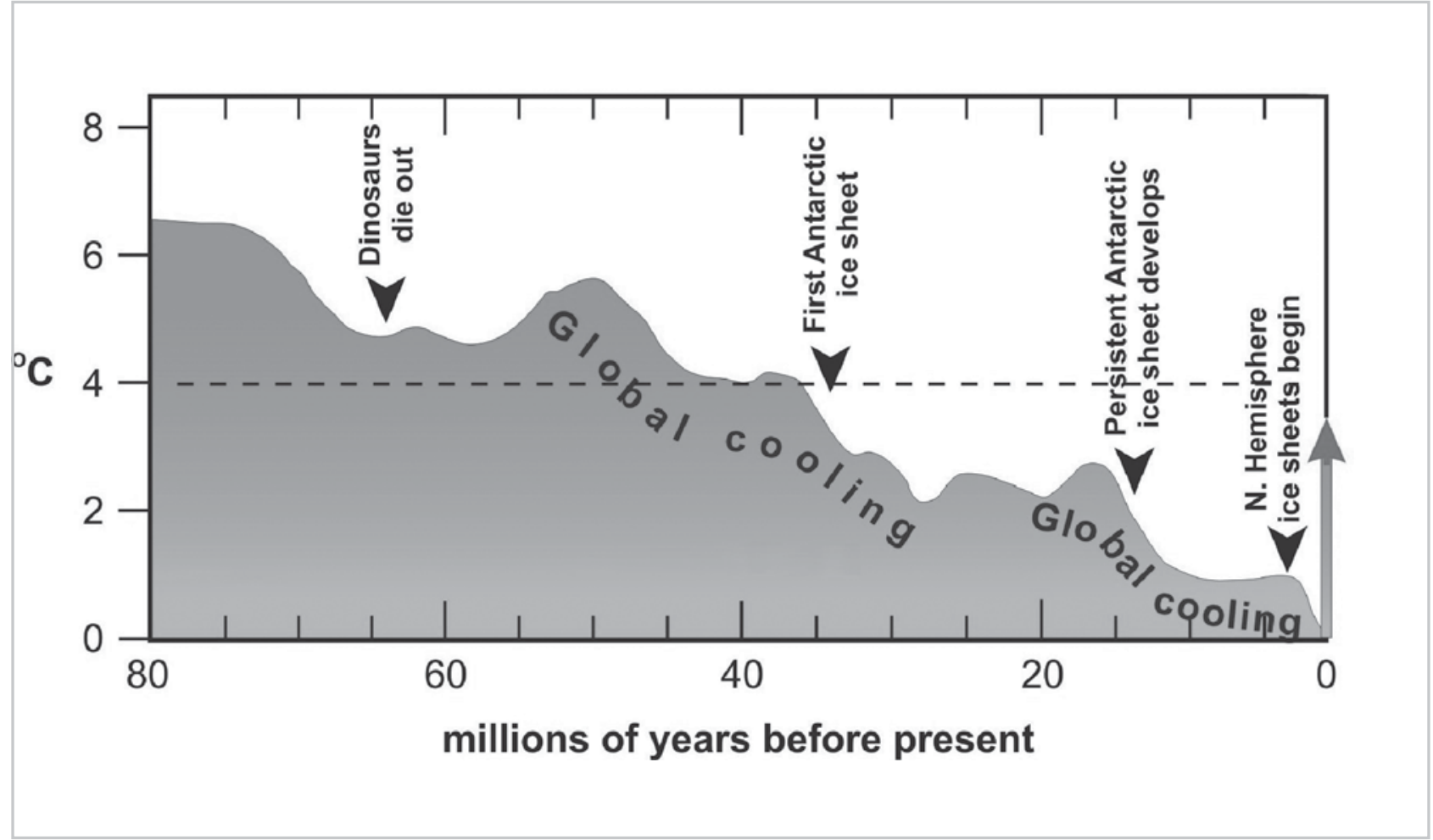

Figure 2: Temperature over the last 400,000 years, based on oxygen isotope measurements from ice cores at Vostok Station, Antarctica. ${ }^{21}$

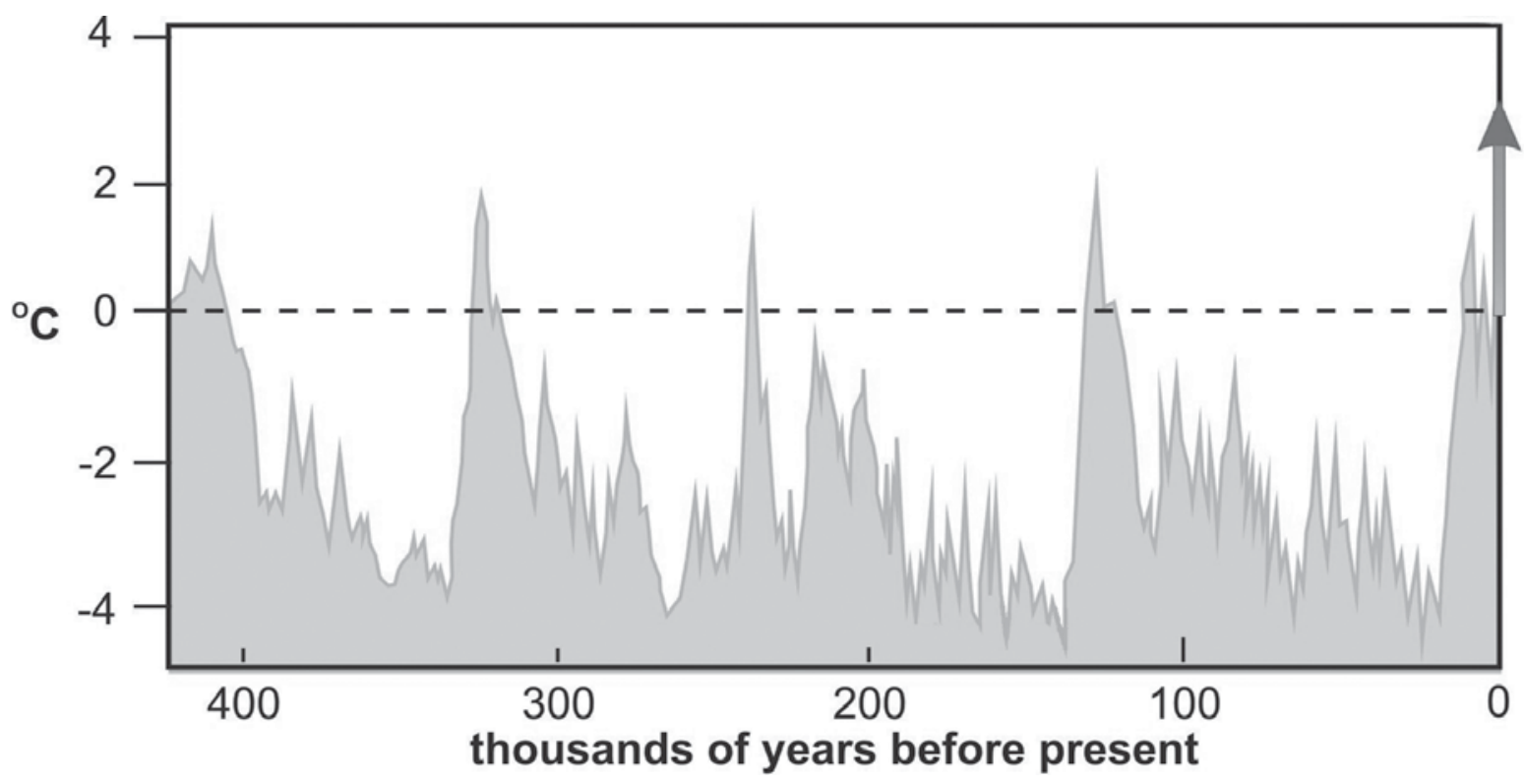


Figure 3. Temperature over the last 1,000 years based on high resolution 'proxy' data from both hemispheres. ${ }^{22}$

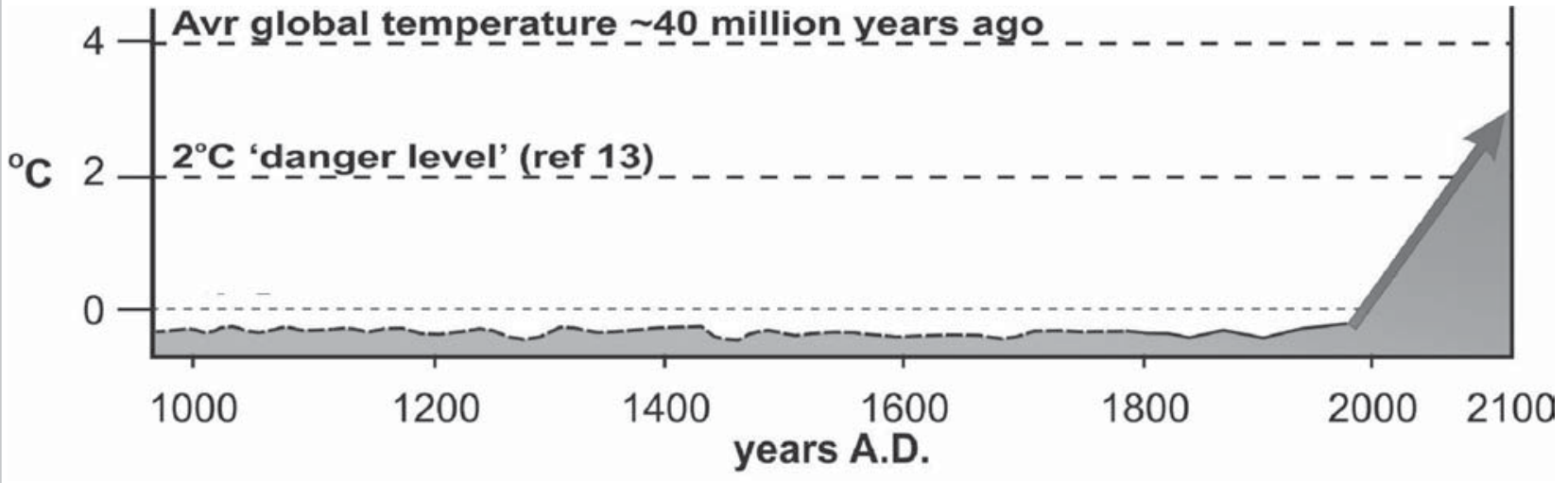

ourselves - Homo sapiens, or 'wise man' - the developed world (and the developing world, which has yet to reach our level of excess) will succeed in maintaining all of our societies, and our civilisation, by adapting to a low energy lifestyle and reducing the current level of atmospheric pollution. Some regions and cultures will do it better than others, but the prospects for all societies becoming truly sustainable in a stable global environment will increase with commitments to that goal at all levels.

The Kyoto Protocol, with all its limitations or deficiencies, is currently the only international collective commitment. The agreement, and those who are working to advise on and implement it, deserve our support - not as the answer in itself, but as an umbrella for progress in the right direction.

19 Kerr, R.A. (2004) 'News Focus - three degrees of consensus', Science, 305, pp.932-4.

20 Crowley, T.J. and K. Kim (1995) 'Comparison of longterm greenhouse projections with the geologic record', Geophysical Research Letters, 22(8), pp.933-6.

21 Petit, J.R. et al. (1999) 'Climate and atmospheric history of the past 420,000 years from the Vostok ice core, Antarctica', Nature, 399 pp.429-36.

22 Mann, M.E. and P.D. Jones (2003), 'Global surface temperatures over the past two millennia', Geophysical Research Letters, 30(15), p.4.
Figures 1-3 show changes in average global temperature compared with today's average on three different timescales. The average projected increase for the doubling of $\mathrm{CO} 2$ levels, which is expected by the end of this century on current projections, is shown as an arrow at the right of each diagram. ${ }^{19}$

Note: The measured range of temperature from glacial to interglacial in Antarctic ice cores is in fact $10^{\circ} \mathrm{C}$, reflecting enhanced polar sensitivity to temperature change, but is scaled here to $5^{\circ} \mathrm{C}$ to correspond with the known temperature difference in average global temperature between glacial and interglacial climate.

Peter Barrett is Professor of Geology at Victoria University of Wellington and Director of the Antarctic Research Centre. He has been chief scientist for a series of Antarctic projects over the last three decades drilling off the coast for climate history. He was awarded the Felipe Ippolito award for Antarctic science by the Italian Academy of Humanities and Sciences in 2001, and the NZ Association of Scientists' lifetime achievement award, the Marsden Medal, in 2004. 